\title{
A comparison of cardiovascular risk factors for ten antipsychotic drugs in clinical practice
}

This article was published in the following Dove Press journal:

Neuropsychiatric Disease and Treatment

18 March 2013

Number of times this article has been viewed

\author{
Robert Bodén ${ }^{1,2}$ \\ Gunnar Edman 3,4 \\ Johan Reutfors ${ }^{2}$ \\ Claes-Göran Östenson ${ }^{3}$ \\ Urban Ösby 3,4 \\ 'Department of Neuroscience, \\ Psychiatry, Uppsala University, \\ Uppsala, Sweden; ${ }^{2}$ Department \\ of Medicine Solna, Centre for \\ Pharmacoepidemiology, Karolinska \\ Institutet, Stockholm, Sweden; \\ ${ }^{3}$ Department of Molecular Medicine \\ and Surgery, Karolinska Institutet, \\ Stockholm, Sweden; ${ }^{4}$ Department of \\ Psychiatry, Tiohundra AB, Norrtälje, \\ Sweden
}

\begin{abstract}
It is well known that abdominal obesity, dyslipidemia, and insulin resistance are highly prevalent in patients receiving maintenance treatment with antipsychotics, but there is limited knowledge about the association between cardiovascular risk factors and treatment with antipsychotic drugs. In this naturalistic study we investigated a sample of 809 antipsychotictreated patients from Swedish psychosis outpatient teams. Cardiovascular risk factors (eg, metabolic syndrome, homeostasis model assessment of insulin resistance, and low-density lipoprotein values) were measured, and their associations to current antipsychotic pharmacotherapy were studied. Ten antipsychotic drugs were compared in a stepwise logistic regression model. For the patients, the presence of the components of metabolic syndrome ranged from $35 \%$ for hyperglycemia to $64 \%$ for elevated waist circumference. Hypertriglyceridemia was associated with clozapine (odds ratio [OR] $=1.81,95 \%$ confidence interval [CI] 1.08-3.04), reduced highdensity lipoprotein with both clozapine and olanzapine (OR $=1.73,95 \%$ CI 1.01-2.97; and $\mathrm{OR}=2.03,95 \% \mathrm{CI} 1.32-3.13)$, hypertension with perphenazine $(\mathrm{OR}=2.00,95 \% \mathrm{CI} 1.21-3.59)$, and hyperglycemia inversely with ziprasidone (OR $=0.21,95 \% \mathrm{CI} 0.05-0.89)$ and positively with haloperidol $(\mathrm{OR}=2.02,95 \%$ CI $1.18-3.48)$. There were no significant relationships between any of the antipsychotic drugs and increased waist circumference, homeostasis model assessment of insulin resistance, or low-density lipoprotein levels. In conclusion, treatment with antipsychotic drugs is differentially associated with cardiovascular risk factors, even after adjusting for waist circumference, sex, age, and smoking.
\end{abstract}

Keywords: adverse metabolic effects, antipsychotic drugs, cardiovascular risk factors, HOMA-IR, metabolic syndrome

\section{Introduction}

Compared with the general population, patients with severe mental illness have an increased risk of morbidity and mortality from cardiovascular disease. ${ }^{1-4}$ A factor contributing to the cardiovascular disease risk profile is metabolic adverse effects of antipsychotic drugs, such as weight gain, dyslipidemia, and disturbances of glucose homeostasis..$^{5-9}$ Clustering of these factors has been made in various definitions of so-called metabolic syndrome that have been widely used to assess and communicate the risk of type 2 diabetes mellitus and cardiovascular disease. ${ }^{10}$

Two antipsychotic drugs in particular, clozapine and olanzapine, have the most pronounced obesogenic, dyslipidemic, and diabetogenic adverse effects. ${ }^{5-9,11,12}$ The diabetogenic effect has mainly been ascribed to increased central obesity and insulin resistance. ${ }^{6}$ A direct pharmacological effect of clozapine and olanzapine, promoting insulin resistance, has been observed both in animal studies and in studies on nonobese patients, even
Correspondence: Robert Bodén Department of Neuroscience, Psychiatry, Ing 153 tr, SE-75I 85 Uppsala, Sweden

Tel $+46186 I I 5243$

Fax +4618515810

Email robert.boden@neuro.uu.se 
though genetic risk factors for metabolic syndrome might differ between animals and humans. ${ }^{13-16}$ Aripiprazole and ziprasidone are considered to be the antipsychotic drugs associated with the fewest metabolic adverse effects. ${ }^{5,7-9,17}$ First-generation antipsychotic drugs (eg, perphenazine and haloperidol) have also been associated with weight gain, but to a lesser degree than clozapine and olanzapine. ${ }^{5,7,8}$ Although there are many studies on metabolic adverse effects of antipsychotic drugs, most of the current knowledge is derived from pharmaceutical trials with nonrepresentative patient samples and few investigated antipsychotics. ${ }^{6,9,12}$ The results from available naturalistic comparative studies are equivocal as to whether there is a clinically important differential effect between antipsychotic drugs on insulin resistance and dyslipidemia. ${ }^{11,18,19}$

The aim of this study was to compare the associations between ten antipsychotic drugs and cardiovascular risk factors in a naturalistic sample of patients with psychosis, mainly schizophrenia or schizoaffective disorder, with antipsychotic maintenance treatment.

\section{Methods}

This is a cross-sectional study. The study protocol was approved by the Stockholm Regional Ethics Committee (04-447/4). Patients were recruited from psychosis outpatient clinics mainly in Stockholm County, Sweden between 2005 and 2010 to the Swedish Study of Metabolic Risks in Psychosis. The clinics are responsible for treatment of all outpatients with long-term psychotic disorders, mainly schizophrenia, in their catchment areas. As part of a general health screening, patients in regular clinical treatment were asked to participate in the study. The original sample comprised 932 participants. All patients in the study gave informed consent. In an analysis from one of the participating clinics, 119 individuals agreed to participate and 36 (23\%) declined. There were no differences in weight or body mass index between participants and nonparticipants, but those who declined were older ( 52 years vs 48 years). The other participating clinics did not record the rate of nonparticipation.

The diagnostic criteria in the Diagnostic and Statistical Manual of Mental Disorders, Fourth Edition (DSM-IV) were used in the diagnostic procedure. Patients were assessed with a psychiatric questionnaire containing information on diagnosis, global assessment of level of functioning and clinical global impression, duration of illness, duration of treatment, and all present medications, including nonpsychotropic drugs. Medication and dosage were recorded and confirmed by case notes when necessary. Patients were also asked about coronary heart disease, diabetes, and hypertension among first-degree relatives. Somatic health was assessed with a questionnaire about coronary heart disease, diabetes, and hypertension, as well as alcohol and tobacco use. Blood pressure, weight, height, and waist circumference were measured. Patients received written instructions to fast overnight before venous blood sampling. Serum glucose was assayed using the glucose oxidase method, and immunoreactive insulin was measured by an in-house radioimmunoassay. Triglyceride (TG), high-density lipoprotein (HDL), and low-density lipoprotein (LDL) cholesterol levels were measured by the Karolinska University Hospital laboratory. Homeostasis model assessment of insulin resistance (HOMA-IR) was calculated as described by Matthews et al. ${ }^{20}$

From the original sample of 932 patients, those with no antipsychotic drug $(n=96)$ were excluded from all further analysis. Four antipsychotic drugs (chlorpromazine, $n=4$; chlorprothixene, $\mathrm{n}=2$; paliperidone, $\mathrm{n}=1$; and thioridazine, $\mathrm{n}=1$ ) were very uncommon, and those patients were also excluded from the study. Nineteen patients had missing data on the components of metabolic syndrome. Thus, the final sample comprised 809 patients with antipsychotic drug treatment. All patients with antidiabetic medication $(n=14)$ were excluded from the analysis of HOMA-IR. Patients with antipsychotic polypharmacy $(n=136)$ were included in the descriptive part of the study but excluded from the main analysis comparing the associations between the ten antipsychotics and cardiovascular risk factors.

Main outcome measures were the components of metabolic syndrome: hyperglycemia, hypertriglyceridemia, reduced HDL levels, hypertension, and elevated waist circumference. Increased HOMA-IR and LDL were also assessed as outcome variables.

The criteria for metabolic syndrome according to the joint criteria from the International Diabetes Federation and National Cholesterol Education Program were used: waist circumference $\geq 102 \mathrm{~cm}$ in males and $\geq 88 \mathrm{~cm}$ in females; elevated fasting plasma glucose $\geq 5.6 \mathrm{mmol} / \mathrm{L}$, or drug treatment for elevated glucose or a diabetes diagnosis; elevated TG levels $\geq 1.7 \mathrm{mmol} / \mathrm{L}$, or drug treatment for dyslipidemia; reduced HDL levels $<1.0 \mathrm{mmol} / \mathrm{L}$ in males and $<1.3 \mathrm{mmol} / \mathrm{L}$ in females, or drug treatment for dyslipidemia; and elevated blood pressure (BP): systolic BP $\geq 130 \mathrm{mmHg}$ or diastolic $\mathrm{BP} \geq 85 \mathrm{mmHg}$, or antihypertensive drug treatment. ${ }^{10}$ Thus, for example, a patient with antidiabetic treatment was considered to have serum glucose of $\geq 5.6 \mathrm{mmol} / \mathrm{L}$. A similar approach was used for LDL, so that patients treated with lipid-lowering drugs were considered as having an increased LDL level. 


\section{Statistical analysis}

All variables were summarized as mean and standard deviation for continuous variables, and median and interquartile ranges for variables with skewed distributions. Categorical variables were presented as numbers (n) and percentages. The cardiovascular risk factors, comprising each dichotomous metabolic syndrome component, as well as HOMA-IR and LDL, both dichotomized at the median, were defined as dependent variables in separate models. The main analyses comprised stepwise logistic regression models, where the association between the ten most frequent antipsychotic drugs and each of the cardiovascular risk factors was analyzed by entering each drug as an independent variable in the same model. Age, sex, and smoking were considered potential confounders and were also entered into the stepwise (forward) logistic regression model. Age was divided into 10-year age groups. Waist circumference was regarded as the most important mediator of the other cardiovascular risk factors, and as we were interested in the differential metabolic effects of using various antipsychotics (disregarding the effects of abdominal obesity), we also included waist circumference in all stepwise logistic regression models, except when waist circumference was the dependent variable.

\section{Results}

Demographic and clinical characteristics are summarized in Table 1. More than two-thirds of the patients had schizophrenia or schizoaffective disorder. Olanzapine and risperidone were the two most frequently used antipsychotics, whereas flupentixol, ziprasidone, and quetiapine were the least common (Table 2). Metabolic syndrome was present among $44 \%$ of both male and female patients. The proportions of patients fulfilling the criteria for each of the components of the metabolic syndrome varied from $30 \%$ for elevated TG in women to $74 \%$ for waist circumference in women (Table 3). Mean body mass index was $29.0 \mathrm{~kg} / \mathrm{m}^{2}$ (standard deviation = 5.9). Median HOMA-IR was 4.2 with an interquartile range of 4.2 .

The associations between the components of metabolic syndrome and use of specific antipsychotic drugs are presented in Table 4. Hypertriglyceridemia was associated with clozapine (odds ratio $[\mathrm{OR}]=1.81,95 \%$ confidence interval [CI] 1.08-3.04). Reduced HDL was related to both clozapine and olanzapine (OR $=1.73,95 \%$ CI 1.01-2.97; and $\mathrm{OR}=2.03,95 \% \mathrm{CI} 1.32-3.13)$. Hypertension was associated with perphenazine $(\mathrm{OR}=2.00,95 \% \mathrm{CI}$ 1.21-3.59). Hyperglycemia was inversely associated with ziprasidone $(\mathrm{OR}=0.21,95 \% \mathrm{CI} 0.05-0.89)$ and
Table I Demographic and clinical characteristics in 809 patients with antipsychotic maintenance treatment

\begin{tabular}{ll}
\hline Variable & $\mathbf{n}(\%)$ \\
\hline Age, years & \\
Mean & 46.9 \\
SD & 12.2 \\
Male & $453(56)$ \\
Education, I2 years or more & $289(36)$ \\
Diagnosis & \\
Schizophrenia & $473(59)$ \\
Schizoaffective disorder & $85(11)$ \\
Delusional disorder & $48(6)$ \\
Psychosis NOS & $106(13)$ \\
Bipolar disorder & $40(5)$ \\
No diagnosis/other diagnosis \\
Antipsychotic treatment, years & $57(7)$ \\
Median & 16 \\
IQR & 17.0 \\
Number of hospitalizations & \\
Median & 3 \\
IQR & 4.0 \\
Duration of previous hospitalizations, months & \\
Median & \\
IQR & 10.5 \\
Smokers & $342(43)$ \\
\hline
\end{tabular}

Note: ancluding autism spectrum disorders, organic psychosis, and personality disorders.

Abbreviations: IQR, interquartile range; NOS, not otherwise specified; SD, standard deviation.

positively associated with haloperidol $(\mathrm{OR}=2.02,95 \% \mathrm{CI}$ 1.18-3.48). There was no significantly different association between any of the antipsychotic drugs and increased waist circumference.

Male sex was significantly associated with hypertriglyceridemia and hypertension, whereas female sex was associated with elevated waist circumference. Higher age was significantly associated with lower HDL levels and with increased BP.

Table 2 Antipsychotic drug use and prevalence of metabolic syndrome in 809 patients with antipsychotic maintenance treatment

\begin{tabular}{|c|c|c|}
\hline Drug treatment & n (\%) & Metabolic syndrome $n$ (\%) \\
\hline \multicolumn{3}{|l|}{ Antipsychotic monotherapy } \\
\hline Aripiprazole & $62(8)$ & $20(35)$ \\
\hline Clozapine & $76(9)$ & $33(45)$ \\
\hline Flupentixol & $23(3)$ & $9(39)$ \\
\hline Haloperidola $^{a}$ & $64(8)$ & $34(54)$ \\
\hline Olanzapine & $138(17)$ & $60(45)$ \\
\hline Perphenazine $^{a}$ & $75(9)$ & $31(43)$ \\
\hline Quetiapine & $28(4)$ & $10(39)$ \\
\hline Risperidone $^{\mathrm{a}}$ & $138(17)$ & $56(42)$ \\
\hline Ziprasidone & $22(3)$ & $9(43)$ \\
\hline Zuclopenthixol $^{\mathrm{a}}$ & $55(7)$ & $24(44)$ \\
\hline Antipsychotic polypharmacy & $128(16)$ & $70(57)$ \\
\hline
\end{tabular}

Note: aral or depot injectable. 
Table 3 Patients fulfilling the criteria for the specific components of metabolic syndrome in $809^{a}$ patients with antipsychotic maintenance treatment

\begin{tabular}{llll}
\hline Risk factors & $\begin{array}{l}\text { Total } \\
\text { n (\%) }\end{array}$ & $\begin{array}{l}\text { Men } \\
\text { n (\%) }\end{array}$ & $\begin{array}{l}\text { Women } \\
\text { n (\%) }\end{array}$ \\
\hline Elevated waist circumference, males $^{\mathrm{b}}$ & $532(66)$ & $269(59)$ & $263(74)$ \\
Hyperglycemia $^{\mathrm{c}}$ & $25 \mathrm{I}(34)$ & $\mathrm{I} 40(34)$ & $\mathrm{III}(35)$ \\
Elevated triglyceride levels $^{\mathrm{d}}$ & $312(40)$ & $208(48)$ & $\mathrm{I} 04(30)$ \\
Reduced levels of high-density $^{\text {lipoprotein }}{ }^{\mathrm{e}}$ & $439(56)$ & $244(56)$ & $\mathrm{I} 95(56)$ \\
Elevated blood pressure $^{\mathrm{f}}$ & & & \\
\hline
\end{tabular}

Notes: a'Sporadic missing values appear in all measures; ${ }^{b}$ waist circumference $\geq 102 \mathrm{~cm}$ in males and $\geq 88 \mathrm{~cm}$ in females; ${ }^{C}$ serum glucose $\geq 5.6 \mathrm{mmol} / \mathrm{L}$, or drug treatment for elevated glucose or a diabetes diagnosis; ${ }^{d}$ triglycerides $\geq 1.7 \mathrm{mmol} / \mathrm{L}$, or drug treatment for dyslipidemia; ehigh-density lipoprotein levels: $<1.0 \mathrm{mmol} / \mathrm{L}$ in males and $<1.3 \mathrm{mmol} / \mathrm{L}$ in females, or drug treatment for dyslipidemia; 'systolic blood pressure $\geq 130 \mathrm{~mm} \mathrm{Hg}$ or diastolic $\geq 85 \mathrm{~mm} \mathrm{Hg}$, or antihypertensive drug treatment

The stepwise logistic regression models showed no significantly different associations between any of the antipsychotic drugs and having a high HOMA-IR or a high LDL (lowest $P$-values were 0.27 for HOMA-IR and 0.09 for LDL).

\section{Discussion}

The main finding of this study was that after adjusting for age, sex, smoking, and waist circumference, cardiovascular risk factors differed between antipsychotic drugs currently used in clinical practice. Clozapine was associated with a worse lipid profile, with increased hypertriglyceridemia and reduced HDL; olanzapine was associated with reduced HDL; perphenazine was associated with hypertension; haloperidol was associated with hyperglycemia; and ziprasidone was associated with reduced frequency of hyperglycemia.

Increased glucose levels in patients treated with haloperidol have previously been observed in randomized controlled trials but also in clozapine-, risperidone-, and olanzapine- treated patients. ${ }^{21,22}$ The lack of association with other antipsychotics in our study might reflect the differences between a randomized controlled trial and the selection effects in a naturalistic study such as the present one. In our study, ziprasidone was inversely associated with hyperglycemia. This finding is in accordance with the fasting blood glucose changes reported from the Clinical Antipsychotic Trials of Intervention Effectiveness (CATIE), ${ }^{7}$ as well as with glycated hemoglobin changes in a long-term trial of olanzapine versus ziprasidone, ${ }^{23}$ which can be contrasted by another trial not finding any significant difference in fasting glucose levels between those two drugs. ${ }^{24}$

We found that clozapine and olanzapine were associated to dyslipidemia, which is concordant with the findings from a recent naturalistic Norwegian study. ${ }^{18}$ However, in the clozapine trial in phase II of CATIE, no differences in lipid levels were observed, ${ }^{25}$ but the rates of dyslipidemia were similar to our study. The TG criterion was met in $40 \%$ of all patients in our study, compared with $49 \%$ in CATIE. ${ }^{26}$ The proportion of patients in our study meeting the HDL criterion was $56 \%$ in males and $57 \%$ in females, compared with $49 \%$ in males and $63 \%$ in females in CATIE.

The finding in our study that perphenazine was associated with hypertension was surprising. To our knowledge, only CATIE has previously investigated perphenazine and hypertension. In contrast to our results, in CATIE there was no difference between the investigated antipsychotic drugs concerning new cases of hypertension. ${ }^{27}$ However, our result should be interpreted with caution due to the cross-sectional study design. We observed a higher prevalence of hypertension than in CATIE ( $61 \%$ vs $48 \%$ ), which might also account for some of the discrepancy. ${ }^{26}$ Further, our patients are slightly older than the patients in CATIE ( 47 years vs 41 years), and

Table 4 Association between antipsychotic drugs with components of metabolic syndrome

\begin{tabular}{|c|c|c|c|c|c|}
\hline & Elevated WC & Elevated TG & Reduced HDL & Elevated BP & Elevated glucose \\
\hline \multicolumn{6}{|l|}{ Antipsychotics ${ }^{a}$} \\
\hline Olanzapine & ns & ns & $2.03(1.32-3.13)$ & ns & ns \\
\hline Perphenazine & ns & ns & ns & $2.00(1.12-3.59)$ & ns \\
\hline Ziprasidone & ns & ns & ns & ns & $0.21(0.05-0.89)$ \\
\hline Haloperidol & ns & ns & ns & ns & $2.02(1.18-3.48)$ \\
\hline Clozapine & ns & I.8I (1.08-3.04) & 1.73 (1.0I-2.97) & ns & ns \\
\hline Elevated WC & $\mathrm{N} / \mathrm{A}$ & $2.81(1.95-4.04)$ & $3.50(2.46-4.98)$ & $2.69(1.89-3.83)$ & ns \\
\hline Female gender & I.84 (I.33-2.55) & $0.35(0.25-0.49)$ & ns & $0.43(0.30-0.62)$ & ns \\
\hline $\mathrm{Age}^{\mathrm{b}}$ & ns & ns & $0.69(0.60-0.80)$ & I.5I (I.30-I.75) & ns \\
\hline Smoking & ns & ns & I.53 (I.09-2.15) & ns & ns \\
\hline
\end{tabular}

Notes: Odds ratios ( $95 \%$ confidence intervals) calculated by stepwise logistic regressions simultaneously investigating ten antipsychotics used as monotherapy, waist

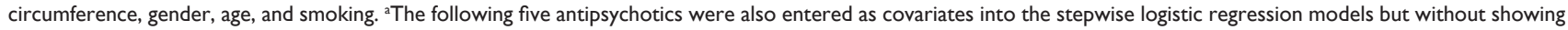
any significant association with any of the investigated components: aripiprazole, flupentixol, quetiapine, risperidone, and zuclopenthixol; bage was classified into I0-year categories and incrementally compared when calculating the odds ratios.

Abbreviations: BP, blood pressure; HDL, high-density lipoprotein; ns, nonsignificant; TG, triglycerides; WC, waist circumference. 
there was a higher proportion of males with elevated waist circumference (59\% vs 37\%), but similar proportions for females (74\% vs 73\%).

A study in northern Sweden investigated antipsychotic drugs and metabolic syndrome in 269 schizophrenia outpatients with a mean age of 46 years and with similar proportions of patients with elevated waist circumference as in our sample. ${ }^{28}$ They reported a similar prevalence of hypertension in patients treated with conventional antipsychotics as those treated with clozapine or olanzapine, but a lower prevalence of hypertension (44\%) compared with our study (61\%). However, a European multicenter study observed a higher prevalence of hypertension in the first-generation antipsychotic group compared with the second-generation group. ${ }^{29}$

The prevalence of the components of metabolic syndrome in our study population of psychosis outpatients was considerably higher than in the Swedish general population retrieved cohort described by Hilding et al. ${ }^{30}$ They found an abnormal glucose regulation in $9.4 \%$ of the men and in $5.6 \%$ of the women, ${ }^{30}$ compared with our observation that $34 \%$ of our patients had hyperglycemia. Furthermore, when comparing the prevalence of elevated waist circumferences with other studies, there are vast differences. In the Hilding et al study, $12 \%$ of the male and $24 \%$ of the female participants had elevated waist circumference, ${ }^{30}$ compared with $59 \%$ of the males and $74 \%$ of the females in our study. A population-based study, Multinational MONItoring of trends and determinants in CArdiovascular disease(MONICA), investigated nondiabetic women and men in northern Sweden with a median age of 50 years. The prevalence of hypertension was $45 \%$ in the MONICA study, compared with the $61 \%$ in our study. ${ }^{31}$ Dyslipidemia (elevated TG, low HDL, or both) was reported in $44 \%$ of the men and $30 \%$ of the women in the MONICA study; in our study, low HDL was evident in $56 \%$ in both sexes. The prevalence of metabolic syndrome in our study was $44 \%$, which is in the lower range compared with previous reports of the prevalence of metabolic syndrome in schizophrenia $(37 \%-63 \%){ }^{32}$ The prevalence of metabolic syndrome in the polypharmacy group was $57 \%$, which is comparable with a previous study reporting a $50 \%$ prevalence. ${ }^{33}$

The major strength of this study was the consecutive patient sampling in a naturalistic setting from psychiatric outpatient clinics with a population responsibility for longterm treatment of patients with schizophrenia and other nonaffective psychoses. The inclusion criteria were broad with few exclusion criteria. Thus, the clinical representativeness of our sample promotes the generalizability of the findings. Another important strength is that the study could compare ten antipsychotic drugs used in clinical practice.

The major limitation was the cross-sectional design, precluding inference of causality between drug exposure and outcome. For instance, an observed association may not be due to the drug itself but rather could be an association between other characteristics of patients being prescribed a certain drug. However, cross-sectional studies can yield important new hypotheses. When using observational data of drug treatment from naturalistic settings, there is inevitably an issue of confounding by indication, ie, prognostic factors may influence treatment decisions. Thus, patients who have gained excessive weight, becoming prediabetic and with a pathogenic lipid profile, may have had their antipsychotic medication switched to a less metabolically active compound before entering the study. This clinical selection process may therefore conceal a true association, suggesting that some of the associations found in this study could have been stronger if no such selection processes had taken place. Another limitation is that only one of the participating clinics recorded the rate of nonparticipation.

Confounding by indication may have influenced the results, in that patients with an elevated waist circumference may have already been switched from more obesogenic antipsychotics to less metabolically adverse drugs but still have a poor metabolic status. However, by including waist circumference in the stepwise logistic regression model, we tried to assess the separate contribution of each antipsychotic drug after adjusting for the contribution by abdominal obesity for all the other components of metabolic syndrome. It is also important to emphasize that as all antipsychotics were analyzed in the same model, a similar association between, for example, waist circumference and all of the included antipsychotics would give a nonsignificant result, because it was the difference between the antipsychotics that was assessed. Moreover, to further control potential confounding effects, age, sex, and smoking were added to the regression model. Age was highly correlated to years with previous use of antipsychotic drugs (data not shown), which means that by adjusting for age we also controlled for duration of antipsychotic exposure.

\section{Conclusion}

Our findings showed that treatment with ten different antipsychotic drugs in clinical practice was differentially associated with established cardiovascular risk factors, even after adjusting for potential confounders such as age, sex, smoking, and waist circumference. To further explore these suggested 
associations, more pragmatic randomized controlled trials comparing the metabolic risk of several commonly used antipsychotics are called for, especially with a focus on dyslipidemia with clozapine and olanzapine, hyperglycemia with haloperidol, and hypertension with perphenazine.

\section{Acknowledgment}

The Swedish Study of Metabolic Risks in Psychosis was supported by ALF Grants 20060100 and 20080022 from the Stockholm County Council and Karolinska Institutet, by grants from the Department of Drug Management and Informatics, Stockholm County Council, by ALF Grants from the Uppsala County Council, and by grants from the Söderström-Königska Foundation.

\section{Disclosure}

Robert Bodén, Johan Reutfors, and Claes-Göran Östenson have no financial disclosures. Gunnar Edman has been a consultant for AstraZeneca and Janssen-Cilag, and his wife is a shareholder in AstraZeneca. Urban Ösby has received honoraria as a speaker or adviser or for attending congresses from AstraZeneca, Bristol-Myers Squibb, Janssen-Cilag, Eli Lilly, and Pfizer, and grant support from Bristol-Myers Squibb and Janssen-Cilag.

\section{References}

1. Ösby U, Brandt L, Correia N, Ekbom A, Sparén P. Excess mortality in bipolar and unipolar disorder in Sweden. Arch Gen Psychiatry. 2001;58(9):844-850.

2. Ösby U, Correia N, Brandt L, Ekbom A, Sparén P. Mortality and causes of death in schizophrenia in Stockholm County, Sweden. Schizophr Res. 2000;45(1-2):21-28.

3. Hennekens CH, Hennekens AR, Hollar D, Casey DE. Schizophrenia and increased risks of cardiovascular disease. Am Heart J. 2005;150(6): 1115-1121.

4. De Hert M, Detraux J, van Winkel R, Yu W, Correll CU. Metabolic and cardiovascular adverse effects associated with antipsychotic drugs. Nat Rev Endocrinol. 2012;8(2):114-126.

5. Kahn RS, Fleischhacker WW, Boter H, Davidson M, Vergouwe Y, Keet IP, et al. Effectiveness of antipsychotic drugs in first-episode schizophrenia and schizophreniform disorder: an open randomised clinical trial. Lancet. 2008;371(9618):1085-1097.

6. Newcomer JW. Second-generation (atypical) antipsychotics and metabolic effects: a comprehensive literature review. CNS Drugs. 2005;19 Suppl 1:1-93.

7. Meyer JM, Davis VG, Goff DC, McEvoy JP, Nasrallah HA, Davis SM, et al. Change in metabolic syndrome parameters with antipsychotic treatment in the CATIE schizophrenia trial: prospective data from phase 1. Schizophr Res. 2008;101(1-3):273-286.

8. Allison DB, Mentore JL, Heo M, Chandler LP, Cappelleri JC, Infante $\mathrm{MC}$, et al. Antipsychotic-induced weight gain: a comprehensive research synthesis. Am J Psychiatry. 1999;156(11):1686-1696.

9. Rummel-Kluge C, Komossa K, Schwarz S, Hunger H, Schmid F, Lobos CA, et al. Head-to-head comparisons of metabolic side effects of second generation antipsychotics in the treatment of schizophrenia: a systematic review and meta-analysis. Schizophr Res. 2010;123(2-3):225-233.
10. Alberti KG, Eckel RH, Grundy SM, Zimmet PZ, Cleeman JI, Donato KA, et al. Harmonizing the metabolic syndrome: a joint interim statement of the International Diabetes Federation Task Force on Epidemiology and Prevention; National Heart, Lung, and Blood Institute; American Heart Association; World Heart Federation; International Atherosclerosis Society; and International Association for the Study of Obesity. Circulation. 2009;120(16):1640-1645.

11. van Winkel R, De Hert M, Wampers M, Van Eyck D, Hanssens L, Scheen A, et al. Major changes in glucose metabolism, including new-onset diabetes, within 3 months after initiation of or switch to atypical antipsychotic medication in patients with schizophrenia and schizoaffective disorder. J Clin Psychiatry. 2008;69(3): 472-479.

12. Leucht S, Corves C, Arbter D, Engel RR, Li C, Davis JM. Secondgeneration versus first-generation antipsychotic drugs for schizophrenia: a meta-analysis. Lancet. 2009;373(9657):31-41.

13. Houseknecht KL, Robertson AS, Zavadoski W, Gibbs EM, Johnson DE, Rollema H. Acute effects of atypical antipsychotics on whole-body insulin resistance in rats: implications for adverse metabolic effects. Neuropsychopharmacology. 2006;32(2):289-297.

14. Newcomer JW, Haupt DW, Fucetola R, Melson AK, Schweiger JA, Cooper BP, et al. Abnormalities in glucose regulation during antipsychotic treatment of schizophrenia. Arch Gen Psychiatry. 2002;59(4): 337-345.

15. Henderson DC, Cagliero E, Copeland PM, Borba CP, Evins E, Hayden D, et al. Glucose metabolism in patients with schizophrenia treated with atypical antipsychotic agents: a frequently sampled intravenous glucose tolerance test and minimal model analysis. Arch Gen Psychiatry. 2005;62(1):19-28.

16. Melkersson KI, Dahl ML. Relationship between levels of insulin or triglycerides and serum concentrations of the atypical antipsychotics clozapine and olanzapine in patients on treatment with therapeutic doses. Psychopharmacology (Berl). 2003;170(2):157-166.

17. Leucht S, Komossa K, Rummel-Kluge C, Corves C, Hunger H, Schmid F, et al. A meta-analysis of head-to-head comparisons of second-generation antipsychotics in the treatment of schizophrenia. Am J Psychiatry. 2009;166(2):152-163.

18. Birkenaes AB, Birkeland KI, Engh JA, Faerden A, Jonsdottir H, Ringen PA, et al. Dyslipidemia independent of body mass in antipsychotic-treated patients under real-life conditions. $J$ Clin Psychopharmacol. 2008;28(2):132-137.

19. Birkenaes AB, Birkeland KI, Friis S, Opjordsmoen S, Andreassen OA. Hormonal markers of metabolic dysregulation in patients with severe mental disorders after olanzapine treatment under real-life conditions. J Clin Psychopharmacol. 2009;29(2):109-116.

20. Matthews DR, Hosker JP, Rudenski AS, Naylor BA, Treacher DF, Turner RC. Homeostasis model assessment: insulin resistance and betacell function from fasting plasma glucose and insulin concentrations in man. Diabetologia. 1985;28(7):412-419.

21. Lindenmayer JP, Czobor P, Volavka J, Citrome L, Sheitman B, McEvoy JP, et al. Changes in glucose and cholesterol levels in patients with schizophrenia treated with typical or atypical antipsychotics. $\mathrm{Am}$ J Psychiatry. 2003;160(2):290-296.

22. Saddichha S, Manjunatha N, Ameen S, Akhtar S. Diabetes and schizophrenia - effect of disease or drug? Results from a randomized, double-blind, controlled prospective study in first-episode schizophrenia. Acta Psychiatr Scand. 2008;117(5):342-347.

23. Kinon BJ, Lipkovich I, Edwards SB, Adams DH, Ascher-Svanum H, Siris SG. A 24-week randomized study of olanzapine versus ziprasidone in the treatment of schizophrenia or schizoaffective disorder in patients with prominent depressive symptoms. J Clin Psychopharmacol. 2006;26(2):157-162.

24. Breier A, Berg PH, Thakore JH, Naber D, Gattaz WF, Cavazzoni P, et al. Olanzapine versus ziprasidone: results of a 28 -week double-blind study in patients with schizophrenia. Am J Psychiatry. 2005;162(10): 1879-1887. 
25. McEvoy JP, Lieberman JA, Stroup TS, Davis SM, Meltzer HY, Rosenheck RA, et al. Effectiveness of clozapine versus olanzapine, quetiapine, and risperidone in patients with chronic schizophrenia who did not respond to prior atypical antipsychotic treatment. Am J Psychiatry. 2006;163(4):600-610.

26. McEvoy JP, Meyer JM, Goff DC, Nasrallah HA, Davis SM, Sullivan L, et al. Prevalence of the metabolic syndrome in patients with schizophrenia: baseline results from the Clinical Antipsychotic Trials of Intervention Effectiveness (CATIE) schizophrenia trial and comparison with national estimates from NHANES III. Schizophr Res. 2005;80(1): 19-32.

27. Daumit GL, Goff DC, Meyer JM, Davis VG, Nasrallah HA, McEvoy JP, et al. Antipsychotic effects on estimated 10-year coronary heart disease risk in the CATIE schizophrenia study. Schizophr Res. 2008;105(1-3):175-187.

28. Hägg S, Lindblom Y, Mjörndal T, Adolfsson R. High prevalence of the metabolic syndrome among a Swedish cohort of patients with schizophrenia. Int Clin Psychopharmacol. 2006;21(2):93-98.
29. Falissard B, Mauri M, Shaw K, Wetterling T, Doble A, Giudicelli A, et al. The METEOR study: frequency of metabolic disorders in patients with schizophrenia. Focus on first and second generation and level of risk of antipsychotic drugs. Int Clin Psychopharmacol. 2011;26(6):291-302.

30. Hilding A, Eriksson AK, Agardh E, Grill V, Ahlbom A, Efendic S, et al. The impact of family history of diabetes and lifestyle factors on abnormal glucose regulation in middle-aged Swedish men and women. Diabetologia. 2006;49(11):2589-2598.

31. Hu G, Qiao Q, Tuomilehto J, Balkau B, Borch-Johnsen K, Pyorala K. Prevalence of the metabolic syndrome and its relation to all-cause and cardiovascular mortality in nondiabetic European men and women. Arch Intern Med. 2004;164(10):1066-1076.

32. De Hert M, Schreurs V, Vancampfort D, Van Winkel R. Metabolic syndrome in people with schizophrenia: a review. World Psychiatry. 2009;8(1):15-22.

33. Correll CU, Frederickson AM, Kane JM, Manu P. Does antipsychotic polypharmacy increase the risk for metabolic syndrome? Schizophr Res. 2007;89(1-3):91-100.
Neuropsychiatric Disease and Treatment

\section{Publish your work in this journal}

Neuropsychiatric Disease and Treatment is an international, peerreviewed journal of clinical therapeutics and pharmacology focusing on concise rapid reporting of clinical or pre-clinical studies on a range of neuropsychiatric and neurological disorders. This journa is indexed on PubMed Central, the 'PsycINFO' database and CAS

\section{Dovepress}

The manuscript management system is completely online and includes a very quick and fair peer-review system, which is all easy to use. Visit http://www.dovepress.com/testimonials.php to read real quotes from published authors. 